\title{
RUMOS DA CIVILIZAÇÃO plantadores fluminenses na abertura de estradas e canais
}

\author{
Ana Lucia Nunes Penha*
}

\begin{abstract}
RESUMO
Objetiva-se apresentar aspectos sobre a construção do Canal Campos-Macaé, obra realizada no período de 1845 a 1872, enfatizando a atuação dos fazendeiros regionais na realização do projeto que exigiu capital político e recursos públicos vultosos. A análise considera aspectos da economia e da política fluminense face à formação e à consolidação do Estado Imperial, à expansão das atividades agroexportadoras da província e ao protagonismo dos plantadores na abertura dos caminhos.
\end{abstract}

Palavras-chave: Província Fluminense; Canal Campos-Macaé; Política

\begin{abstract}
This study aims to present the aspects on the construction of the Macaé-Campos channel. Such construction work was performed in the period from 1845 to 1872 emphasizing the local farmers participation on a political and public "bank stock hungry" project. The present analysis considers economic and political aspects of Fluminense's region before the formation and consolidation of the Imperial State, the province's agricultural exportation activities and the farmers' role in opening of the water paths.
\end{abstract}

Keywords: Fluminense Province; Campos-Macaé Channel; Politcs

\footnotetext{
* Doutora em História pela UFF e professora da Rede Municipal de Ensino de Macaé e da FAFIMA - Faculdade de Ciências e Letras de Macaé.
} 


\section{Introdução}

Em 19 de outubro de 1837 o vice-presidente da Província do Rio de Janeiro, José Ignácio Vaz Vieira, autorizou através do Decreto $n^{\circ} .85$ que fossem tomadas as providências necessárias para o levantamento da planta de um canal de navegação ligando o interior do norte da província ao litoral. Este deveria partir da cidade de Campos dos Goytacazes e seguir em direção à Vila de Macaé, vindo dar na foz do rio Macaé, onde as mercadorias seriam desembarcadas e conduzidas ao porto de Imbetiba, a pouca distância dali, e postas em novas embarcações antes de seguirem para o Rio de Janeiro.

Segundo o mesmo decreto, da Vila de Macaé o extenso canal deveria prosseguir em direção ao Porto das Caixas, próximo à Niterói, aproveitando os cursos d'água da região. Para tanto o canal seguiria pela lagoa de Imboassica, passando pelas cabeceiras do rio das Ostras e do São João, alcançando a lagoa de Juturnaíba e, em seguida, os rios Bacachá, Bonito, Porto das Caixas e Macacu (RIO DE JANEIRO, 1844).

A província fluminense ocupava uma posição incomum, comparada às outras províncias brasileiras, devido à proximidade do Rio de Janeiro, capital do Império e principal centro financeiro e exportador do país. A condição privilegiada da cidade e seu porto remontavam aos tempos coloniais. Tornada capital da colônia em 1763 e depois sede da Corte portuguesa, em 1808, a cidade foi elevada ainda à capital do país independente, em 1822, mudanças que refletiram diretamente sobre sua dinâmica de funcionamento. Quanto à Província do Rio de Janeiro, esta ganhou gestão própria, separada da cidade do Rio em 1834 . A partir da década de 1830, novas mudanças incidiram sobre o porto carioca e a província fluminense, dada a expansão da cultura cafeeira e a crescente importância que as exportações brasileiras passariam a ganhar no cenário nacional e nos mercados internacionais.

Vale lembrar que essa preeminência política e econômica do centro-sul, notadamente da cidade do Rio de Janeiro e província, tem sido comumente apontada pela historiografia como elemento fundante do processo de centralização do Estado, consolidado no pós-1850 com base no privilegiamento dos interesses ligados à expansão cafeeira (Mattos, 1990:86).

Nesse sentido, considerando a participação dos plantadores na formação e centralização do Estado e o crescente predomínio dos cafeicultores sobre os demais setores de agricultura fluminense, buscamos tecer algumas considerações sobre a construção do Canal Campos-Macaé - representação dos interesses diretos dos fazendeiros do norte da província, inseridos no jogo político do império, notadamente no primeiro reinado, quando a 
administração provincial contraiu avultada dívida junto ao governo central para a realização daquela obra.

A construção do canal viria favorecer a Baixada Campista, área situada no norte da província, que se destacara na produção canavieira desde fins do século XVIII, mas não apenas. Beneficiava também a produção de Cantagalo, região centro-norte que já apresentava, em meados da década de 1830, crescente produção de café e alimentos. O canal, portanto, traria benefícios para a administração provincial e para os plantadores do norte e centro-norte fluminense, ainda que seus principais protagonistas fossem os plantadores dos dois municípios que deram nome ao canal.

As dificuldades de transporte da produção da província fluminense e mineira até o litoral eram antigas e a busca de soluções para o escoamento das mercadorias do norte fluminense integrou a pauta de discussões na assembleia desde as primeiras legislaturas. Embora fossem conhecidos os problemas dos campistas para condução das cargas pelo rio Paraíba até que elas alcançassem o porto de São João da Barra, foi, a partir da formação da assembleia provincial, em 1834, que a discussão veio à tona e o projeto de construção do canal foi considerado por aquelas primeiras administrações.

Outra chave de compreensão para a aprovação do projeto, a principal a ser analisada neste artigo, reside no alinhamento político de José Carneiro da Silva, o visconde de Araruama, e demais fazendeiros regionais nos quadros do Partido Conservador. Nascera na Regência a iniciativa da sua construção, ganhando forma no calor do Regresso conservador, em 1837, período em que foram lançadas as bases que dariam sustentação ao Estado Imperial sobre a direção intelectual e moral dos saquaremas.

O sentido ideológico e a importância política da obra transparecem nos relatórios provinciais e escritos entusiasmados de José Carneiro da Silva e fazendeiros regionais da década de 1830 e 1840, nos quais eram celebrados os benefícios econômicos e o engenho da construção que, concorrendo para a grandeza da província, tornara-se um dos símbolos da civilização e de orgulho da jovem nação independente.

Temos, portanto, no referido projeto a convergência de fatores econômicos, políticos e ideológicos que, combinados, concorreram para a liberação de recursos públicos para a realização da obra, iniciada na década de 1840. Entretanto, o agravamento dos problemas técnicos impetrados à navegação pelo canal e o prolongamento das obras por mais duas décadas coincidiram com o avanço das estradas de ferro na província e o abandono da obra pela administração provincial. 


\section{Um canal fluminense: breve história}

Idealizado desde fins do século XVIII pelo bispo campista Azeredo Coutinho, o canal ligando Campos a Macaé era a solução nascida entre os plantadores e comerciantes regionais para dar fim ao problema antigo da Baixada Campista: o escoamento da produção do interior até a cidade do Rio de Janeiro, principal centro consumidor e exportador de produtos como açúcar, aguardente, mel, café, feijão, algodão, azeite de mamona, milho, arroz, doces e diversos tipos de madeiras, entre outros.

Em fins do Setecentos, quando ocorreu na Inglaterra o que Paul Mantoux chamou de “febre de canais", já essas construções haviam se expandido em países como França, Holanda e Estados Unidos (Mantoux, 1988; Landes, 1994), alimentando, em terras fluminenses, a ideia do projeto de ligação do norte da província ao litoral.

A construção do canal era assim tomada como a redenção de todo o atraso imputado pela colonização. Através da jovem nação independente, estava destinada a ingressar no concerto das nações civilizadas e prósperas. A ideia de uma espécie de destino manifesto era encorajada pelo reconhecimento das riquezas e dos recursos naturais do país: a fertilidade do solo, a amenidade do clima, a abundância das terras e matas virgens e das águas e vias naturais de navegação, como se apreende da obra Memórias sobre canais, estradas e a utilidade que resulta a civilização, a agricultura e o comércio da construção dessas obras, publicada por José Carneiro da Silva em 1836 (Silva, 1836).

José Carneiro da Silva esteve à frente dos projetos de desenvolvimento de sua região desde o período joanino, como é possível apreender de seu necrológico, escrito em 1862 (ESPAÇO CULTURAL JOSÉ CARLOS BARCELOS (Doravante ECJCB) - Pereira Filho, 1864). Como observa Parron, aproximando-se do círculo dos Bragança e empenhando-se na abertura de caminhos pelo hinterland fluminense ao lado do irmão, o fazendeiro investiu capitais próprios na abertura de estradas, construção de pontes e esgotamento dos pântanos da região. Na assembleia provincial fluminense, alinhou-se aos políticos do Regresso e tornou-se um dos principais bastiões do Partido Conservador no norte da província, ${ }^{1}$ atuando como deputado provincial nas legislaturas de 1835 a 1837, de 1838 a 1839 e de 1844 a 1847.

A coordenação das escavações do Canal Campos-Macaé e a administração das verbas ficaram por quase duas décadas sobre a responsabilidade de José Carneiro, que obteve o título

\footnotetext{
${ }^{1}$ O norte da província fluminense viria a se tornar uma das regiões-chave do partido conservador (Parron,
} 2011:152). 
de barão de Araruama em 1844. O proeminente fazendeiro coordenou a comissão responsável pela obra e mobilizou os plantadores e comerciantes daqueles municípios em torno de suas vantagens, entre as quais o saneamento de áreas alagadas e o controle dos mosquitos, responsáveis por febres e doenças como a malária, na região.

Outros canais nasciam na mesma época como o de Itaguaí (Moreira, 2005), no sul fluminense, ligando a mesma localidade ao porto do Casaca, próximo à foz do rio de Itaguaí. A concessão foi feita a Francisco José Cardoso que, como o visconde de Araruama, também atuava como deputado provincial quando foi sancionada a lei que autorizava a obra, em 1836. Também o Canal do Nogueira, em Campos, tivera o projeto aprovado no início da década de 1830. Entretanto, as vantagens do Canal Campos-Macaé pareciam superar as dos demais, como observado na fala do presidente de província, o campista João Caldas Viana que, em 1843, chegou a referir-se a ele como a "Veneza Brasileira" (RIO DE JANEIRO, n. 1843, L 1, pp. 42-43).

A planta do Campos-Macaé fora autorizada mas ficou sem execução devido à morte do engenheiro Henrique Luiz de Niemeyer Bellegarde, encarregado do seu traçado. A retomada do projeto ocorreu durante a gestão de Honório Hermeto Carneiro Leão, quando Caldas Viana instituiu, no ano de 1843, a comissão que deveria traçar o plano e o orçamento das obras.

Novo impulso para as obras veio por meio da Lei $n^{\circ} .333$ de 11 de maio de 1844, sancionada pelo conselheiro Tomás Gomes dos Santos, pela qual o governo central concedia à província o crédito extraordinário de 1.432 contos de réis para sua construção (RIO DE JANEIRO, 1844). O vultoso valor aproximava-se, como pudemos verificar, da média do orçamento das receitas da província para o período de 1851-1856, que ficava em torno de 1.600 contos e se destinava a despesas com instrução, obras públicas, força pública e outras (RIO DE JANEIRO. Relatórios provinciais anos de 1850-1855).

O canal teria a extensão de 41.779 braças, aproximadamente 100 quilômetros de extensão, e as escavações, iniciadas em 1845, mobilizaram os plantadores e comerciantes daquelas localidades. A obra ficou dividida em seções que foram entregues à arrematação e pagas pela Tesouraria da província através de títulos da dívida pública. A comissão que controlava esses procedimentos era composta por José Carneiro da Silva, João Carneiro da Silva, o major Bento Gonçalves da Silva e o tenente coronel do corpo de engenheiros Ernesto Augusto Cesar Eduardo de Miranda. O planejamento e inspeção ficavam a cargo da Diretoria 
de Obras Públicas da província, que deveria fiscalizar e ressarcir os 49 arrematantes envolvidos na obra até o ano de 1848, após a conclusão dos trechos contratados.

Foi na gestão do presidente de província Aureliano de Souza e Oliveira Coutinho, visconde de Sepetiba, ocorrida entre 1844 e 1848, que as obras tiveram maior incremento. Seu ritmo retrocedeu nos anos seguintes e o prazo para a conclusão, previsto para o ano de 1848 ou, no máximo, 1849, não foi cumprido, arrastando-se por mais de duas décadas.

Era recorrente a participação dos proprietários locais na execução de projetos de obras públicas nas localidades onde residiam. Destacam-se tanto na história do canal como na de outras obras de infraestrutura do império os nomes de seus empreendedores. Na região do Vale do Paraíba fluminense, por exemplo, importantes proprietários de terras moveram recursos a fim abrir os caminhos de ligação entre o porto do Rio de Janeiro e as Minas Gerais. Alguns deles despontaram, mais tarde, no cenário político do Império, como Ignácio José de Souza Werneck, responsável pela abertura, em 1813, da Estrada do Comércio, destinada a facilitar o transporte da produção do oeste fluminense e do sul e oeste mineiros. Outras estradas beneficiaram os produtores de café do Vale, como a da Estrada da Polícia, aberta em 1820 pelo intendente de Polícia do Rio de Janeiro, Paulo Fernandes Vianna. Começava na Vila de Iguaçu e seguia pela Serra do Mar em direção à fazenda de José Rodrigues Alves, onde, mais tarde, seria fundada a cidade de Vassouras.

Também a Presidente Pedreira, antes denominada Estrada da Bocaina do Mendes, em funcionamento nos anos 1850, e idealizada por José Clemente Pereira, proprietário da fazenda das Cruzes, beneficiou as lavouras de Vassouras. Iniciava na Pavuna e tomava a direção de Santa Cruz dos Mendes alcançando o rio Paraíba do Sul e seguindo em direção à província mineira (Novaes, 2008).

O protagonismo de fazendeiros e negociantes nos investimentos de infraestrutura, no entanto, não era uma especificidade da economia escravista brasileira. Na Inglaterra de fins do século XVII, os investimentos públicos e privados estiveram voltados para a ampliação do sistema pluvial, fazendo com que, em 1750, houvesse mais de mil milhas de vias navegáveis. As inversões de capitais aumentariam ainda mais nas décadas de 1750 e 1760, com o surgimento dos primeiros canais de navegação e das leis de barreiras de pedágio, aprovadas já havia meio século pelo Parlamento inglês (Landes, 1994:55). Na construção do Canal do Erie, na América, verificou-se a influência das ligações políticas na execução de obras públicas. O canal construído no início do século XIX cumpriu importante papel no processo de ocupação e conquista das terras do oeste da América do Norte, ligando os estados de Búfalo e Albany. 
Sua iniciativa deveu-se a DeWitt Clinton, sobrinho e secretário de George Clinton, governador de Nova Iorque (McNeese, 2009:3). Esses exemplos situam-se no quadro da expansão da economia capitalista mundial em formação, para a qual o sistema de transporte terrestre, integrado aos portos, desempenhou papel fundamental na inserção desses mercados nacionais/regionais no circuito das trocas internacionais.

A iniciativa de grupos privados, o apoio político e financeiro do Estado e a necessidade de integração do interior com as cidades litorâneas em conexão com as nações civilizadas estiveram presentes na construção do Erie. No imaginário dos colonos que fizeram a marcha para o oeste, aquele canal representou a ligação do inóspito interior, assolado pelos índios, com o litoral que ligava a América ao mundo civilizado europeu.

Em terras fluminenses, o canal distanciava-se da grande missão integradora que lhe fora atribuída: a de ligar o interior ao litoral, reduzindo as distâncias entre recônditas localidades fluminenses e os portos, por onde se alcançavam as nações civilizadas de alémmar. Em 1850, as obras encontravam-se paradas e, embora os relatórios provinciais não oferecessem maiores explicações, um provável motivo devia-se ao sistema de arrematação envolvendo fazendeiros diferentes, bastando que o atraso das obras de alguns trechos implicasse o prejuízo de outros.

A mudança de orientação da política da província no pós-1850 em decorrência da lei Eusébio de Queirós, que instituíra o fim do tráfico transatlântico, reforçou a previsibilidade quanto ao fim da escravidão trazendo para a pauta das discussões parlamentares o problema da escassez de braços e a necessidade de novos investimentos em infraestrutura. Nas décadas seguintes a Província do Rio de Janeiro e o governo imperial passariam a verter recursos na construção de estradas de ferro, estimulando, por meio da garantia de juros, a criação de companhias com esse fim. Vale lembrar que a primeira ferrovia do Brasil, a Estrada de Ferro Mauá, que uniu o Município de Estrela à Raiz da Serra de Petrópolis, foi inaugurada em 1854 pela Imperial Companhia de Navegação a Vapor e Estrada de Ferro de Petrópolis e contou com capitais privados. Foi dirigida por Irineu Evangelista de Souza.

A inviabilidade da navegação em diversos trechos do canal e a necessidade de constantes melhoramentos, somadas à conjuntura política e econômica da segunda metade do século XIX, que priorizada as ferrovias em função dos interesses da cafeicultura, corroboraram para seu abandono.

Quanto ao estado das obras, era flagrante sua paralisação por quase toda a década de 1850 e crescia a polêmica na assembleia sobre sua continuidade. A decisão de investir 
recursos novos no seu melhoramento justicava-se pelo desperdício que representava a não continuidade dos reparos, considerando os 1.400 contos já investidos na obra até aquele momento. Opiniões como a do deputado Lucas Antonio Monteiro de Barros, alegando que o canal "nenhuma vantagem tinha dado à província", mas apenas havia se tornado um "sorvedouro de rendas" para que os moradores do lugar tirassem dele vantagens, concorriam para o desprestígio da obra entre os deputados provinciais (BIBLIOTECA NACIONAL DO RIO DE JANEIRO - Doravante BNRJ, 1850, n. ${ }^{\circ} 8.399$, p. 2).

$\mathrm{Na}$ assembleia, não faltavam ataques ao canal, a Aureliano de Sousa Oliveira Coutinho, que esteve na Presidência da província quando foram iniciadas as obras, no período de 1844-1848, e ao visconde de Araruama. Entretanto, o prestígio e a liderança política de José Carneiro da Silva permaneciam imbatíveis, ficando ele responsável, como consta em seguidos contratos firmados nos anos seguintes, por empreender os melhoramentos e a finalização das obras do canal.

Isso se deveu, certamente, à trajetória de José Carneiro da Silva, construída desde o período joanino.

\section{José Carneiro da Silva e sua liderança política}

O protagonismo de fazendeiros nas obras de abertura e melhoramento de vias de comunicação no Brasil remontava aos tempos coloniais. Como menciona Fridmam, desde o início do povoamento os colonizadores receberam favores da Coroa, que concedia sesmarias, isenção de serviços militares, imunidade judicial e privilégios fiscais àqueles que abrissem estradas. Por ordem régia, também ficavam autorizados a instalar freguesias e aldeias de repartição em terras indígenas.

Essa prerrogativa cumpriu um importante papel no processo de colonização e povoamento funcionando como viveiro de mão-de-obra cativa e ponto estratégico de defesa do território, o que era revelador da forte relação existente entre o Estado português e a Igreja. Mais tarde, os antigos aldeamentos transformados em paróquias integrariam o mosaico das vilas e cidades coloniais, estimulando a abertura de caminhos para o trânsito de mercadorias e de gentes (Fridman, 2006:132).

Em fins do século XVIII, diante da diminuição da arrecadação aurífera nas Gerais, a administração colonial, movida pelas reformas pombalinas, deu início aos projetos de integração e conhecimento sobre o território propondo a abertura de rios navegáveis e 
estradas. Entretanto, a melhoria dos caminhos só ganharia maior impulso no século XIX, quando da transferência da Corte para o Rio de Janeiro e dos incentivos oferecidos pelo governo joanino aos fazendeiros, através da doação de sesmarias e da abertura e reparo de estradas do interior, o que permitiu maior integração entre a produção mineira e o mercado carioca.

Essa política voltada para a concentração de terras, como afirma Lenharo, foi "uma das condições básicas para que se desse a proliferação da economia cafeeira". Sobre este ponto, destaca o autor que o aumento da demanda carioca por gêneros de subsistência e as medidas de incremento da comunicação interna empreendidas no período joanino favoreceram, no quadro de desenvolvimento da economia cafeeira em terras fluminenses, a expansão e afirmação de dois grupos ligados à economia mercantil de abastecimento, destacando-se, especialmente nos anos 1830, o grupo formado na região cafeeira do Vale do Paraíba, que "ganhará identidade própria e constituir-se-á na base social do movimento regressista e, portanto, do conservadorismo no Brasil” (Lenharo, 1979:30).

Outro grupo ligado ao abastecimento, e que ocupava as antigas áreas integradas ao mercado interno colonial, também vira no aumento daquelas demandas a oportunidade de expansão de seus negócios. Após a abdicação de D. Pedro I, alguns políticos interioranos ligados a eles despontariam no cenário das novas configurações políticas da regência (Ibidem).

José Carneiro da Silva destacou-se como um desses políticos interioranos ligados aos setores de subsistência fluminense desde fins do século XVIII e cuja riqueza originara-se da criação de gado e da atividade açucareira sendo, como vimos, o principal chefe político regional e protagonista da construção do Canal Campos-Macaé. Nascido em Quissamã, em 1788, quando a região ainda pertencia a Campos, José Carneiro era filho do capitão de milícias Manoel Carneiro da Silva, rico fazendeiro residente na comarca de Campos, e de sua mulher, D. Anna Francisca de Velasco (Faria, 1986:204). Seus pais estabeleceram-se na região onde construíram a casa em Mato de Pipa, ainda hoje existente. Tiveram 10 filhos e quase todos adquiram títulos de nobreza. Ampliaram o prestígio social da família ao contrair matrimônios com pessoas ilustres ou com membros do próprio grupo familiar.

Seus avós paternos foram João Carneiro da Silva, contratador de diamantes no Rio de Janeiro, casado com D. Isabel Nascentes Pinto. A mesma atividade do avô viria a ser desempenhada por um dos tios de José Carneiro, também chamado José Carneiro da Silva e 
que se ocupava da contratação de diamantes na região do Tejuco, nas Gerais (ECJCB Pereira Filho, 1864).

Manoel Carneiro da Silva nasceu em 1743, no Rio de Janeiro, e fixou-se na região norte da mesma capitania por volta de 1779 , onde atuou como capitão dos índios, agricultor e produtor de anil e algodão, produtos que comercializava na praça do Rio de Janeiro. Nessa época, possivelmente, edificou a casa de Mato de Pipa na sesmaria recebida de seu pai, que ia da Lagoa Feia à Lagoa da Ribeira, hoje terras onde estão localizadas as fazendas de Machadinha, Melo e Mato de Pipa (Almeida, 1985).

José Carneiro da Silva era proprietário das fazendas de Mato de Pipa, Quissamã, São Miguel, Mandiquera, Santa Francisca e Machadinha, algumas com engenhos a vapor, possuindo, todas, avultado número de escravos (Oscar, 1985:115-116). Ocupou os cargos de juiz de paz, comandante da Guarda Nacional de Macaé e Capivary e delegado de Polícia, além de atuar como membro correspondente do Instituto Histórico de Paris e da Sociedade Auxiliadora da Indústria Nacional e como sócio fundador do Imperial Instituto Fluminense de Agricultura, entre outros.

Representante de uma aristocracia rural enriquecida pelo açúcar, fez do solar de Quissamã, para onde se mudara em 1826, a principal fazenda da região na primeira metade do século XIX, construída no auge da fase dos engenhos particulares (Marchiori et al, 1987). A fazenda, hoje transformada no Museu Casa de Quissamã, expressava o poderio patriarcal da família Carneiro da Silva. Seus proprietários receberiam títulos do Império, símbolo do poder político e pessoal dos potentados rurais. Em 1847 o monarca Pedro II visitou o norte da Província e foi recebido na residência de José Carneiro da Silva, onde ficou hospedado (Lamego Filho, 1958:91). Nessa ocasião o barão recebeu o título de visconde de Araruama.

A estreiteza no relacionamento entre o fazendeiro e políticos de projeção no Império ajuda a entender o prestígio do visconde que, na qualidade de importante liderança política fluminense, esteve à frente de grandes projetos para a região, como foi o do Canal CamposMacaé.

Como homem de letras, atuou em defesa da lavoura e indústria nacional através de seus escritos, sendo conhecidas as obras Memória Topographica sobre Campos dos Goytacazes, impressa em 1819; Memória sobre canais, estradas e a utilidade que resulta a civilização, a agricultura e o comércio da construção dessas obras, publicada em 1836; e 
outra, escrita em 1838 e assinada por "natural de Campos dos Goitacases", 2 intitulada Memória sobre o comércio dos escravos em que se pretende mostrar que este tráfico é, para eles, antes um bem do que um mal, na qual procurava atenuar os males da escravidão a partir dos benefícios que gozavam os africanos feitos escravos no Brasil. A organicidade demonstrada através da propagação de suas ideias claramente se identificavam ao que Ilmar de Mattos definirá como a "recunhagem" da moeda colonial, através da qual o Reino cedia lugar às nações civilizadas, de um lado, e, de outro, a Coroa se impunha à Região.

Para o autor de Memórias sobre canais, a ideia da construção do Campos-Macaé e de outros canais fluminenses como o da Pavuna, do Nogueira e de Araruama, além de outro a ser projetado na abertura da Barra de Cabo-Frio, representava a chegada do espírito da indústria no país que, recém egresso da condição colonial, era detentor de incomensuráveis riquezas naturais e vasto potencial hídrico, tendo diante de si um futuro grandioso, como se observa nas suas palavras:

(...) a abertura do Canal de Campos a Macaé, além de uma estrada de Cantagalo para aquele município e a ponte sobre o rio Parahyba; os privilégios concedidos à Companhia de Navegação, Comércio e Colonização do Rio-Doce e seus confluentes; a Companhia de Niterói para navegação por vapor em suas enseadas e rios; a de Gongo-soco para a mineração; além de outros concedidos para o melhoramento, ou abertura de novas estradas nesta Província do Rio de Janeiro, assim como em Minas, São Paulo, Bahia e Pernambuco... tudo isto nos dá as mais belas fundadas esperanças de vermos dentro de pouco tempo o comércio interior deste belo País nada ter a invejar aos daquelas potências que se acham mais avançadas na carreira da indústria, e civilização; tendo nós a nosso favor um clima excelente, um terreno rico em produções, e todo retalhado de rios, e lagos, ótimos para desenvolvimento aos sistemas de canalização. (Silva, 1819:29)

Foi com esse espírito que o fazendeiro, possivelmente entre o final da década de 1830 e início de 1840, sugeriu alterações no traçado do Canal Campos-Macaé, a ser construído pelo inglês H. Freese, quem primeiro obteve a concessão para a realização da obra. O manuscrito endereçado a Freese trazia várias considerações justificando que alterações na linha do canal que primavam por sua utilidade para os fazendeiros "a quem a obra particularmente interessava". Inferimos da leitura do documento que o traçado proposto por José Carneiro tinha por objetivo favorecer as fazendas da região, sobretudo as suas, alterando o curso retilíneo de alguns trechos e fazendo-os mais sinuosos. Justificava que o canal, como as obras

\footnotetext{
${ }^{2}$ Sobre a autoria da obra ter sido equivocadamente atribuída ao bispo José Joaquim da Cunha de Azeredo Coutinho, ver Marquese (2005).
} 
públicas feitas nos lugares mais isolados, onde são poucos os grandes proprietários e os recursos, não devia ser como as estradas que iam pelo mesmo curto caminho. ${ }^{3}$

$\mathrm{Na}$ obra de defesa do canal, José Carneiro reportava-se às vantagens da navegação para o desenvolvimento do comércio e indústria através dos tempos a começar pelos assírios, exaltando a grandeza dos templos e palácios da Babilônia, passando pela China e Egito com seus numerosos canais. Descrevia os notáveis diques, aquedutos e galerias subterrâneas existentes na Europa continental, Inglaterra, Escócia, Estados Unidos, Canadá e ressaltava o notável número de canais franceses.

A companhia para a construção do canal seria formada com capitais ingleses, mas não se organizou no prazo estabelecido e a concessão foi perdida em 1835, não havendo outra interessada. Só na década seguinte a administração provincial obteve o crédito do governo central para sua realização, ficando José Carneiro responsável pela direção dos trabalhos. O fazendeiro havia se empenhado em algumas obras, como a da abertura de uma estrada, inaugurada em 1826, comunicando a vila de São Salvador com a Corte, mas a falta de conservação transformaram-na, em pouco mais de dez anos, num vasto atoleiro.

Frustradas as saídas por terra, nos anos 1830 a ideia do canal ressurgia, tendo a seu favor o vigor da produção do norte e centro-norte fluminenses e as ligações políticas que aproximavam aquelas lideranças locais, sobretudo da família dos Araruama, aos dirigentes saquaremas. A esse núcleo, nutrido por Bernardo Pereira de Vasconcelos, Honório Hermeto Carneiro Leão e José da Costa Carvalho, unir-se-iam os demais conservadores e mesmos os Luzias. Isto porque, aliadas às propostas de restauração, os Saquaremas propunham medidas favoráveis à expansão da própria classe.

\section{Agonia do canal}

No caso específico do Canal Campos-Macaé, entendemos que o alinhamento dos fazendeiros do norte da província com os saquaremas foi fundamental para que se efetivasse num primeiro momento o projeto da obra. A administração provincial fluminense registrara nas primeiras legislaturas a passagem de políticos como Joaquim José Rodrigues Torres, visconde de Itaboraí, e Paulino Soares de Sousa, visconde de Uruguai. Juntamente com Eusébio de Queirós, cujo filho, Eusébio de Queirós Matoso da Câmara, viria a ser genro do visconde de Araruama, esses homens tomaram para si a direção da nação, empreendendo a

\footnotetext{
${ }^{3}$ ECJCB - Resposta aos quesitos de [J H] Freese por sua ordem numérica, pp. 1-2. Manuscrito de José Carneiro da Silva, s/d.
} 
sua centralização em torno da unidade saquarema privilegiando a região de agricultura mercantil-escravista e dentro desta o "Sul". Orientavam-se por uma visão tripartite da sociedade, dividida entre o mundo do governo, composto pela "boa sociedade" e o mundo do trabalho, ambos pertencentes à esfera da ordem e com o qual o Estado se relacionava. O outro mundo, o da desordem, não era alcançado pelos ditames da ordem. Compunha-se de homens livres, pobres, os desordeiros que não se inseriam no universo da agroexportação. Os dirigentes saquaremas se incumbiam, assim, de reproduzir a hierarquia entre os "três mundos" que marcavam as diferenças entre pessoas no Império do Brasil.

A classe senhorial se distinguiria na trajetória de construção do Estado e especialmente a Província do Rio de Janeiro, por meio da expansão cafeeira, viveria de modo intenso a crescente inserção do café no comércio mundial.

Entretanto, na medida em que se efetivava a centralização da Coroa nos anos $1850 \mathrm{e}$ os grupos identificados aos setores fluminenses, voltados para a agroexportação, consolidavam o império do café, novas clivagens surgiriam no interior da classe e o canal, antigo símbolo do poder provincial, submergia aos poucos.

Cresciam na assembleia provincial, em 1850, as acusações quanto à falta de transparência com a qual eram conduzidas as obras. Os deputados, reunidos em assembleia, já se mostraram cautelosos em relação aos gastos públicos, e o presidente João Darrigue Faro anunciou a suspensão, no segundo semestre daquele ano, de todas as obras feitas por administração, exceto as da Estrada Normal de Estrela, da Colônia de Petrópolis e do Canal de Campos a Macaé, por serem feitas com créditos especiais do empréstimo (BNRJ, 1850:2).

Como mencionado, as coisas não iam bem com o canal e já se havia esgotado o crédito extraordinário destinado à sua construção. A assembleia provincial, considerando os gastos anteriores com a obra, decidiu pela destinação de verbas para sua conclusão, o que causou polêmica entre os deputados (RIO DE JANEIRO, 1850:18).

No ano seguinte, novo contrato feito com o visconde de Araruama garantiu a escavação de alguns trechos e limpeza de grande parte do canal. Mas, apesar dos esforços, em 1851 ele ainda não prestava navegação em todas as linhas (RIO DE JANEIRO, 1851:17). Possivelmente, o desconforto causado por essas circunstâncias forçou sua inauguração em dezembro de 1861. Entretanto, em 1867, era completo o seu abandono. A obra havia desprendido quase 2.000 contos de réis sem que desse à navegação suficiente e regular, havendo obstrução pelo desmoronamento de suas margens em diversos lugares (RIO DE JANEIRO, 1867:18). 
Nos anos subsequentes, concessões de exploração da navegação a vapor por 20 anos foram entregues a companhias privadas. Primeiramente ao engenheiro civil Pedro Nolasco Amado Forjaz Paes Leme, que desistiu e, em 1869, transferiu a concessão para o conselheiro João de Almeida Pereira Filho e seu sócio, o bacharel Guilherme de Almeida Magalhães. A companhia formada pretendia estabelecer navegação pelo canal e os rios Macabu, Imbé e Ururahy e estabelecer a ligação do canal com o rio Paraíba (RIO DE JANEIRO, 1869:37; Ver também Sousa, 1935:72-3).

No ano seguinte, Almeida Pereira desistiu do privilégio e Almeida Magalhães, que ficara sozinho no negócio, transferiu para a companhia União Industrial a concessão que recebera, ficando o privilégio prorrogado por mais 20 anos. Entretanto, os trabalhos de melhoria iniciados por esta última foram interrompidos no início de junho de 1874, devido à falência da Companhia. Em 1875, o canal retornou para o controle da administração provincial, quando já então as concessões e subsídios da província e do governo central concentravam-se na expansão das linhas férreas, ficando o extenso canal, que nos anos 1830 simbolizara a grandeza e o ingresso do país no mundo civilizado, relegado ao esquecimento quase completo.

\section{Considerações finais}

Apresentamos um breve relato dos percalços do Canal Campos-Macaé, enfocando alguns aspectos políticos e ideológicos apreendidos da intrigante história dessa obra pública fluminense que agregou em torno de si fazendeiros e negociantes dos dois municípios.

Desejosos de fazerem prosperar suas fazendas e as lavouras e o comércio da região através do transporte de seus produtos até os mercados, os plantadores e comerciantes da região, sobre a liderança do visconde de Araruama, Jose Carneiro da Silva, rasgaram o solo fluminense, entre os anos de 1845 e 1850, período de abertura do canal, unindo lagoas e modificando-se os cursos de rios na região. Os anos seguintes seriam marcados por intermináveis obras de melhoramentos, sem que, contudo, o canal viesse proporcionar a navegação desejada. O Almanaque de Campos assim se refere, no ano de 1886, ao estado do canal, encontrando-se ele

[...] obstruído por um fundo de lodo e pelas areias das ribanceiras, por pipiris e tiriricas e outros vegetais especiais das águas dormentes, sem nenhum cuidado de conservação por parte de quem quer que seja a quem isso compita, atravessando, além de lagoas e brejos, um terreno arenoso e de 
aluvião, que facilmente se esboroa, para pouco tem ele prestado... Ainda assim, presta serviço aos moradores dos sertões do Imbé, Urubu, Ururahy, Lagoa de Cima e Macabu, que por ele conduzem madeiras de construção, lenha, farinha, legumes... (Mello, 1886:35)

Pensamos que, do ponto de vista da técnica e da logística de sua construção, o malogro da obra fosse previsível, e mesmo anunciada por seus contemporâneos mais atentos. Entretanto, a concepção do projeto e sua realização deveu-se em grande parte a elementos de natureza política e ideológica.

Nascido no Regresso, o canal foi acalentado pelos saquaremas como parte de um projeto político de nação centralizada e alinhada aos ideais de civilização. As lideranças conservadoras que emergiram dos anos 1830 tomaram para si a grande obra civilizadora e o canal revestiu-se da simbologia de um tempo. As conjunturas econômicas e políticas da segunda metade do século, entre as quais o privilegiamento dos interesses da agroexportação, a emergência de novos capitais vertidos em estradas de ferro e outros fatores somados a problemas técnicos provavelmente decorrentes de estudos topográficos insuficientes e supressão das eclusas previstas no projeto inicial, além das limitações técnicas da época, a demasiada extensão da obra, que ficou dividida em trechos menores arrematados por diferentes fazendeiros, concorreram para o malogro e posterior abandono da obra.

Hoje abandonado e de águas poluídas, o Canal Campos-Macaé, também chamado canal do "cula", já não serve para navegação; converteu-se em canal de drenagem. Outrora objeto de expectativas e orgulho de seus idealizadores, presta-se a tarefas menos honrosas e encontra-se assoreado em alguns de seus trechos, convertido em receptor de lixo e águas "servidas", lançadas por empresas e residências. Uma parte de seu curso corta o Parque Nacional da Restinga de Jurubatiba, área de preservação reconhecida pela Unesco. Devido ao seu valor histórico e ambiental, foi proposto seu tombamento ao Instituto de Patrimônio Histórico e Artístico Nacional em 2000, sendo aprovado pelo Inepac em 2002. ${ }^{4}$

O Canal Campos-Macaé, que corta os atuais municípios de Campos dos Goytacazes, Quissamã, Carapebus e Macaé, sobrevive, hoje, nos lugares distantes da memória regional.

\footnotetext{
${ }^{4}$ Em julho de 2002, foi encaminhada, ao presidente do Instituto Estadual do Patrimônio Artístico e Cultural, a proposta de "Tombamento do Canal Campos-Macaé em toda sua extensão" e do trecho urbano a ele associado.
} 


\section{Referências Bibliográficas}

ALMEIDA, Eliana C. Cavour P. de; SILVA, Gisela Cunha Carneiro da. A casa de Mato de Pipa. Quissamã, 1985.

BIBLIOTECA NACIONAL DO RIO DE JANEIRO (BNRJ). Diário de Rio de Janeiro, Ano XXIX. 15 de maio de 1850, n. $^{\circ} 8.399$, p. 2.

Diário do Rio de Janeiro, Ano XXIX. 29 de janeiro de 1850, nº 8.312, p. 2.

ESPAÇO CULTURAL JOSÉ CARLOS BARCELOS (ECJCB) - PEREIRA FILHO, João de Almeida. Necrologia de Exm ${ }^{o}$. Sen ${ }^{r}$. Visconde de Araruama. Campos: Typographia Campista - Rua Direita, n. 24. 1864.

. Resposta aos quesitos de [J H] Freese por sua ordem numérica, pp. 1- 2. Manuscrito de José Carneiro da Silva, s/d.

FARIA, Sheila de Castro. Terra e trabalho em Campos dos Goitacases (1850-1920). Dissertação de Mestrado. Instituto de Ciências Humanas e Filosofia. Niterói: UFF, 1986. 204p.

FRIDMAN, Fânia. As cidades e o café. Revista do Rio de Janeiro, n. 18-19, pp. 131-149, jan.-dez. 2006.

LAMEGO FILHO, Albert Ribeiro. Anuário Geográfico do Estado do Rio de Janeiro, n. 11, pp. 1-158, 1958.

LANDES, David. Prometeu desacorrentado - transformação tecnológica e desenvolvimento industrial na Europa ocidental, desde 1750 até a nossa época. Tradução de Vera Ribeiro e revisão de Cesar Benjamim. Rio de Janeiro: Nova Fronteira, 1994.

LENHARO, Alcir. As tropas da moderação: o abastecimento da corte na formação política do Brasil, 1808-1842. São Paulo: Símbolo, 1979.

MANTOUX, Paul. A Revolução Industrial no século XVIII - estudo sobre os primórdios da grande indústria moderna na Inglaterra. Tradução de Sonia Rangel. São Paulo: UNESP/HUCITEC, 1988.

MARCHIORI, Maria Emília Prado et al. Quissamã. Rio de Janeiro: SPHAN, Fundação Nacional Pró-Memória, 6ª diretoria Regional, 1987. 
MARQUESE, Rafael de Bivar. Azeredo Coutinho, visconde de Araruama e a Memória sobre o comércio dos escravos de 1838 - Dossiê História Atlântica: recortes e perspectivas. Revista de História. Departamento de História da Universidade de São Paulo, $\mathrm{n}^{\circ} .152,1^{\circ}$ semestre/ 2005. Disponível em:

<http://www.revistasusp.sibi.usp.br/pdf/rh/n152/a05n152.pdf>

MATTOS, Ilmar R. O Tempo Saquarema: formação do Estado Imperial. 2. ed. São Paulo: Editora HUCITEC, 1990.

McNEESE, Tim. The Erie Canal: Linking the Great Lakes / Tim McNeese (Milestone in American History). New York: Chelsea House, 2009.

MELlO, José Alexandre Teixeira. Campos dos Goytacazes em 1881. Rio de Janeiro: Typographia, Litographia e encadernação a vapor. Lermmert \& C, Rua dos Inválidos, 71, 1886.

MOREIRA, Gustavo A. Cardoso. Uma família no Império do Brasil: os Cardoso de Itaguaí: um estudo sobre economia e poder. Dissertação de Mestrado. Instituto de Ciências Humanas e Filosofia (PPGH). Niterói: UFF, 2005.

NOVAES, Adriano. Caminhos antigos do território fluminense. Instituto Cidade Viva, 2008.

Disponível em http://www.institutocidadeviva.org.br/inventarios/sistema/apcontent/uploads/2008/06/os caminhos... acesso em 01 de fevereiro 2014.

OSCAR, João. Escravidão e Engenhos: Campos, São João da Barra, Macaé, São Fidélis. Rio de Janeiro: Achiamé, 1985.

PARRON, Tâmis. A política da escravidão no Império do Brasil. 1826-1865. Rio de Janeiro: Civilização Brasileira, 2011.

RIO DE JANEIRO. Relatório do Vice-Presidente de Província do Rio de Janeiro na abertura a assembleia legislativa provincial de 05 de março de 1843 acompanhado do orçamento da receita e despesa para o ano de 1843-1844 balanço do exercício findo. Nictheroy: Typographia Nictheroyense de MG de S. Rego, Praça Municipal, n. 1843, L 1, pp. 42-43.

Decreto n. 85 de 19 de outubro de 1837. Rio de Janeiro: Typographia do Diário de N. C. Viana, 1844. Coleção de Leis, Decretos e Regulamentos da Província do Rio de Janeiro (1835-1837).

Lei $333\left(N^{o}\right.$ 36) de 11 de maio de 1844. Rio de Janeiro: Typographia do Diário de N. C. Viana, 1844. Coleção de Leis, Decretos e Regulamentos da Província do Rio de Janeiro (1835-1837). 
Relatório apresentado em cumprimento da circular do Ministério do Império de 11 de março de 1848, ao Exm ${ }^{\circ}$. Presidente de Província do Rio de Janeiro Dr. Luiz Pedreira do Couto Ferraz pelo Exm ${ }^{o}$. Vice-Presidente João Pereira Darrigue Faro, por ocasião de passar-lhe a administração da mesma província. Nictheroy, Typ. de Amaral \& Irmão. 1850. Disponível em: <http://www.crl.edu/brazil/provincial/rio_de_janeiro>

. Relatórios provinciais anos de 1850-1855. Disponível em <http://www.crl.edu/brazil/provincial/rio_de_janeiro>

. Relatório do vice-presidente do Rio de Janeiro o veador João Pereira Darrigue Faro, na abertura da segunda sessão da oitava legislatura da assembleia provincial no dia $1^{o}$ de agosto de 1851. Acompanhado do orçamento da receita para o ano de 1852. Rio de Janeiro. Typ. Universal de Laemmert. Rua dos Inválidos, 61 B. 1851. Disponível em:< http://www.crl.edu/brazil/provincial/rio_de_janeiro>

Relatório apresentado à Assembleia Legislativa Provincial do Rio de Janeiro na $2^{a}$ sessão da décima sexta legislatura no dia 20 de outubro de 1867 pelo Presidente da mesma Província Dr. Esperidião Eloy de Barros Pimentel. Rio de Janeiro. Typographia Universal de Laemmert. Rua dos Inválidos, 61 B, 1867.

- Relatório apresentado à Assembleia Legislativa Provincial do Rio de Janeiro na segunda sessão da décima sétima legislatura no dia 01 de outubro de 1869 pelo vicepresidente Desembargador Diogo Teixeira de Macedo. Rio de Janeiro. Typographia do Diário do Rio de Janeiro, Rua do Ouvidor, 97, 1869.

SILVA, José Carneiro da. Memoria topographica e histórica sobre os Campos dos Goitacazes, com huma noticia breve de suas produções e o commercio - oferecida ao muito alto e muito poderoso Rey e senhor nosso D. João VI. Rio de Janeiro. Imprensa Regia, 1819.

- Memórias sobre canais, estradas e a utilidade que resulta a civilização, a agricultura e o comércio da construção dessas obras. Campos: Typographia de A. J. P. Maya Parahiba, a Ca. Rua do Conselho, n. 94, 1836.

SOUSA, Horácio de. Ciclo áureo - história do $1^{o}$ centenário da cidade de Campos (18351935). Campos: Artes Gráficas. 1935. 